\title{
The Pathway to Decarbonization: Flettner Rotor Application in Maritime Logistics
}

\author{
Muhammad Fakhruriza Pradana ${ }^{1,2 *}$, Bernd Noche ${ }^{1}$, Fikri Abdulhakim Ichsan ${ }^{1}$ \\ ${ }^{1}$ Institute of Transport Systems and Logistics, University of Duisburg-Essen, Forsthausweg 2, 47057 Duisburg, Ger- \\ many \\ ${ }^{2}$ Department of Civil Engineering, University of Sultan Ageng Tirtayasa, Jl. Jend Sudirman Km 3 Cilegon 42435, \\ Indonesia

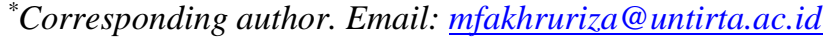

\begin{abstract}
The increasing carbon footprints are forcing international regulators to reform fossil fuels into alternative fuels. Maritime transportation contributes $2.89 \%$ of carbon to the earth. One of the solutions to push this emission (decarbonization) is creating alternative fossil-free energy. The most possible and feasible alternative energy on the open sea is natural wind. But we found that the old technology to capture wind energy in vessels such as kites, rigid sails, and soft sails has large dimensions and is very volatile. Nowadays, Flettner rotor technology is more resilient and achieve high saving fuels in the unpredicted weather condition. This paper uses a narrative literature review to analyze the strengths and weaknesses of the Flettner rotor compared to other wind-assisted ship propulsion (WASP) technologies. The result shows that the Flettner rotor is better in terms of size and fuel efficiency result. Flettner rotor potentially achieves $30 \%$ fuel saving by using only 4 meters of the diameter of the rotor. On the other hand, the challenges of the Flettner rotor are parameter selection of the rotor, the weather condition or weather forecasting accuracy, and the economic aspect.
\end{abstract}

\section{Keywords: Maritime Logistics, Flettner Rotor, WASP technologies, Fuel Efficiency}

\section{INTRODUCTION}

Climate change is a global phenomenon caused by human activity, transforming the unusual condition in temperature, precipitation, and wind [1]. Another dangerous phenomenon is global warming, a trim when the earth's surface temperature and the troposphere increase for an extended period [2]. These two incidents are strictly dangerous for human life; that's why the International maritime organization (IMO) is pressing the vision to eliminate $70 \%$ of carbon intensity by 2050 (compared to the 2008 emissions) [3].

Carbon dioxide is the prime cause of the rising global average temperature. The carbon particle rose rapidly due to the industrial revolution era in the $1700 \mathrm{~s}$ and 1800s [4]. The growth of the human population also drives enormous demand for the maritime logistic sector and create 1,076 million tons of carbon dioxide in a year [5]. The global shipping industries contribute $2.89 \%$ of carbon emissions annually, and it must reform the energy from fossil fuels into alternative fuels [3].
Besides designing, inventing and applying alternative fuels, the speed of vessels and weather conditions also influenced the fuel consumption of ships [6]. Developing an alternative fuel is one of the strategies recommended by IMO. Various alternative fuels such as LNG, hydrogen, natural energy, and battery-powered propulsion [3]. We can still develop the best possible technology, wind-assisted ship propulsion (WASP), from these alternatives. It is very reasonable because of the availability of wind energy in the open sea [7].

Open sea has two potential sources of energy: solar and wind energy. By capturing and optimizing these energies, the ship can sail with unlimited range [7]. Using kites, rigid and soft sails technology will influence the vessel's speed and lifting force by the unpredicted wind angle. In actual weather conditions, the wind angle and velocity change in a short time [8]. However, the Flettner rotor potentially achieves high fuel savings and less sensitivity to unpredictable weather conditions [9].

Flettner rotor is a technology invented in the 1920 s by Anton Flettner, a German engineer. The mechanism 
of Flettner discovered the basic theory of the Magnus effect. The Magnus effect occurs when a rotated object causes a different surface pressure and creates an upward force [10]. An example of this phenomenon is when a basketball or football player spins the ball when throwing it and creating an unusual curve. According to this natural event, we can make a rotational object's upward or lifting force move in the opposite direction [10].

Flettner rotor is a technology that can reduce $\mathrm{NO}_{\mathrm{x}}$, $\mathrm{SO}_{x}, \mathrm{CO}$, and $\mathrm{CO}_{2}$ [11]. The expected lifting force of the Flettner rotor is produced from a spinning object that moving in the opposite direction [10]. Blowing wind around the spinning rotor powered by an electric motor will create different pressure on the surface of the rotor and then generate lift and drag force [12]. The outcome energy of the Flettner rotor depends on the environmental condition, such as the angle of wind and wind velocity. Some studies show that the performance of the Flettner rotor can reduce $0.4 \%-50 \%$ of burned fuel [9].

Weather conditions and sailing routes strongly influencing the performance of the Flettner rotor. The value of aerodynamics force produced by the rotor is mainly dependent on the angular speed, the diameter of the rotor, and free stream velocity [13]. The potential of saving fuel could also increase following the installed rotor number [9].

In this study, the Flettner rotor will be compared and reviewed with another wind-assisted ship propulsion. The growing demand for renewable energy creates a new technical problem to solve and economic interest [14]. The aim of this research will be evidence for the effectiveness and efficiency of the Flettner rotor application in maritime logistics. Each WASP technology will be reviewed according to the dimension, saving fuels, and additional power needed. The weather condition, sailing speed, and economic aspect also will be checked and analyzed.

\section{METHODS}

This study was conducted using a narrative literature review (NLR) approach, where the reviews were based on articles that had a current and robust relationship with the topics discussed. NLR will identify what had been done by other researchers and protect from duplication [15]-[18]. This study is one step before doing in-depth research in the Flettner rotor.

The steps of the approach used are as follows:

- Topic setting

- Search articles on significant sources, e.g. Scopus and the web of science

- Determination of articles that are directly related to the topic
- Synthesis of articles (comparing ideas, reinforcing topics, setting challenges for topics and focusing on topics)

\section{RESULTS AND DISCUSSION \\ 3.1 The superiority of the Flettner rotor}

This section describes the superiority of the Flettner rotor over another technology. There are five popular WASP technology: Flettner rotor, kites, rigid sails, soft sails, and wind turbines [9]. This section will compare the strength and weaknesses of the Flettner rotor with other WASP technologies. Compared to kites and soft sails, the Flettner rotor is the 'friendliest' technology that can perform in any direction and velocity of wind [7]. Furthermore, the dimension of the Flettner rotor is smaller than other technology. The size of kites and soft sails (Dynarig), on averages, are more than $100 \mathrm{~m}^{2}$ with potential fuel savings of only up to $50 \%$. Compared with kites, the manoeuvres of soft sails are pretty safe, secured, and easy to use [19]. The use of soft sails, Flettner rotor, and kites can be seen in Figure 1.

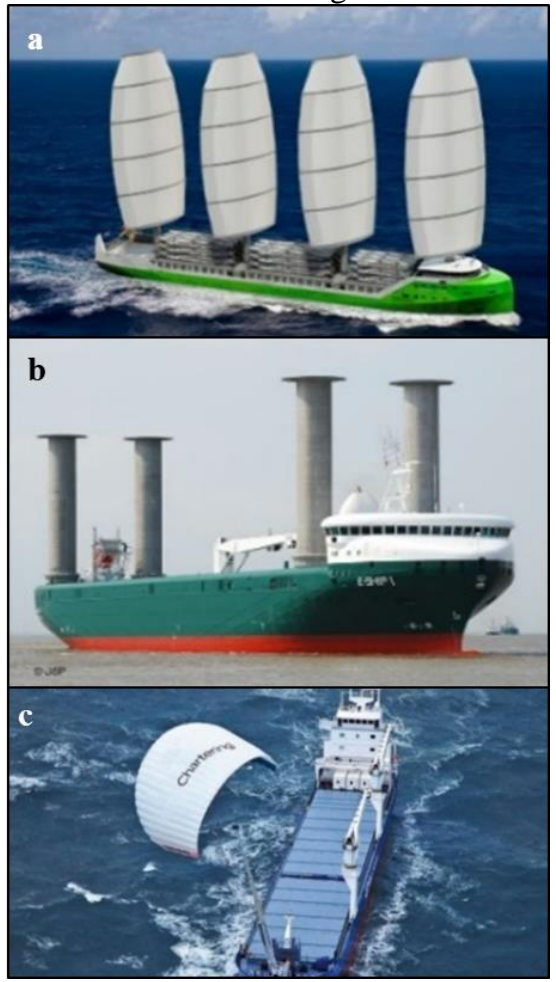

Figure 1. Soft sails (a), Flettner rotor (b), and kites (c) [20] 
Table 1. Review of WASP performance [9].

\begin{tabular}{|c|c|c|c|c|}
\hline Study & Technology & Dimension & Ship type & Savings found \\
\hline [22] & Kites & $\begin{array}{c}a=500 \mathrm{~m} 2 \\
\mathrm{I}=150 \mathrm{~m}\end{array}$ & 50k DWT Tanker & Up to $50 \%$ \\
\hline [23] & Kites & $\begin{array}{c}a=640 \mathrm{~m} 2 \\
\mathrm{I}=600 \mathrm{~m}\end{array}$ & 73k DWT Tanker & $40 \%$ \\
\hline [24] & Kites & $\begin{array}{c}a=500 \mathrm{~m} 2 \\
\mathrm{I}=350 \mathrm{~m}\end{array}$ & $\begin{array}{c}\text { 6k DWT General } \\
\text { cargo }\end{array}$ & $32 \%$ \\
\hline [21] & Kites & $\begin{array}{c}a=400 \mathrm{~m} 2 \\
\mathrm{I}=350 \mathrm{~m}\end{array}$ & 5k DWT Tanker & $9-15 \%$ \\
\hline [24] & Kites & $\begin{array}{c}a=320 \mathrm{~m} 2 \\
\mathrm{I}=300 \mathrm{~m}\end{array}$ & 50k DWT Tanker & $10-50 \%$ \\
\hline [25] & Soft sails & N.A. & $\begin{array}{l}\text { 10k DWT Chemical } \\
\text { tanker }\end{array}$ & $15-35 \%$ \\
\hline [19] & Soft sails & $a=1000 \mathrm{~m} 2$ & Aframax tanker & $5.6 \%$ \\
\hline [26] & Rigid sails (9x) & $h=50, w=20$ & $\begin{array}{c}\text { 180k DWT Bulk Car- } \\
\text { rier }\end{array}$ & $20-30 \%$ \\
\hline [25] & Rigid sails & Unspecified & $\begin{array}{c}\text { 10K DWT Chemical } \\
\text { Tanker }\end{array}$ & $20-60 \%$ \\
\hline \multirow{4}{*}{ [21] } & Rigid sails (3x) & $h=25, w=9$ & 5k DWT Tanker & $5-8 \%$ \\
\hline & Rigid sails (5x) & $h=50, w=17$ & 90k DWT Tanker & $9-13 \%$ \\
\hline & Rigid sails ( $3 x)$ & $h=27, w=10$ & 7k DWT Bulk Carrier & $5-7 \%$ \\
\hline & Rigid sails (5x) & $h=50, w=18$ & $\begin{array}{c}\text { 90k DWT Bulk Car- } \\
\text { rier }\end{array}$ & $18-24 \%$ \\
\hline [19] & Rigid sails & $h=50, w=20$ & Aframax Tanker & $8.8 \%$ \\
\hline \multirow{4}{*}{ [21] } & Wind turbines & $h=20, d=38$ & 5k DWT Tanker & $1-2 \%$ \\
\hline & Wind turbines & $h=20, d=38$ & 90k DWT Tanker & $1-2 \%$ \\
\hline & Wind turbines & $h=20, d=38$ & 7k DWT Bulk Carrier & $1-2 \%$ \\
\hline & Wind turbines & $h=20, d=38$ & $\begin{array}{c}\text { 90k DWT Bulk Car- } \\
\text { rier }\end{array}$ & $2-4 \%$ \\
\hline [25] & Flettner rotor & Unspecified & $\begin{array}{c}\text { 10K DWT Chemical } \\
\text { Tanker }\end{array}$ & $10-50 \%$ \\
\hline [24] & Flettner rotor & $h=35, d=5$ & $\begin{array}{l}\text { 6k DWT General } \\
\text { Cargo }\end{array}$ & $21 \%$ \\
\hline \multirow{4}{*}{ [21] } & Flettner rotor $(2 x)$ & $h=22, d=3$ & 5k DWT Tanker & $5-7 \%$ \\
\hline & Flettner rotor $(3 x)$ & $h=48, d=6$ & 90k DWT Tanker & $9-13 \%$ \\
\hline & Flettner rotor $(2 \mathrm{x})$ & $h=24, d=3.5$ & 7k DWT Bulk Carrier & $5-7 \%$ \\
\hline & Flettner rotor $(2 x)$ & $h=48, d=6$ & $\begin{array}{c}\text { 90k DWT Bulk Car- } \\
\text { rier }\end{array}$ & $17-23 \%$ \\
\hline [27] & Flettner rotor & $h=25, d=4$ & $\begin{array}{c}\text { 17k DWT General } \\
\text { Cargo }\end{array}$ & $14-36 \%$ \\
\hline [13] & Flettner rotor $(2 x)$ & $h=28, d=4$ & $\begin{array}{c}\text { 75k DWT Product } \\
\text { Tanker }\end{array}$ & Up to $30 \%$ \\
\hline \multirow{5}{*}{ [28] } & Flettner rotor $(4 \mathrm{x})$ & $h=27, d=4$ & $\begin{array}{c}\text { 10k DWT General } \\
\text { Cargo/Ro-Lo }\end{array}$ & $8.3-47 \%$ \\
\hline & Flettner rotor $(2 x)$ & $h=18, d=4$ & 10k DWT Ro-Ro & $1.6-9.0 \%$ \\
\hline & Flettner rotor & $h=24, d=4$ & 6k DWT (2.8k pax) & $0.4-2.8 \%$ \\
\hline & Flettner rotor & $h=18, d=3$ & Passenger & $1.0-6.6 \%$ \\
\hline & Flettner rotor $(2 x)$ & $h=30, d=5$ & 110k DWT Tanker & $1.8-4.7 \%$ \\
\hline [19] & Flettner rotor & $h=18, d=3$ & Aframax Tanker & $8.9 \%$ \\
\hline [29] & Flettner rotor & $h=18, d=3$ & $\begin{array}{c}\text { 4k DWT General } \\
\text { Cargo }\end{array}$ & $10-20 \%$ \\
\hline
\end{tabular}


Another technology that has been used is the wind turbine. The usability of wind turbines potentially decreases the fuel consumption by only $1-4 \%$. With height and diameter is 20 and 38 meters, respectively [21], the size and efficiency of a wind turbine are the lowest. Comparing to rigid sails, the dimension of wind turbines is smaller. But the performance of rigid sails for the same type of ship (5k DWT) is better for around 3-6\%, decreasing fuel consumption.

Rigid sail also has a considerable measure and a lot of installation numbers, more than three pieces. Using five rigid sails with height and width 50 and 17 meters sequentially in 9,000 DWT ships will saving around 9$13 \%$ fuel [21]. The savings found of three rigid sails in $7 \mathrm{k}$ DWT is $5-7 \%$. Compared to the Flettner rotor, the result is also not much different. Installed two Flettner rotors in $7 \mathrm{k}$ DWT also potentially decrease the saving found in the same number.

According to the journal review by [9], the dimension of the Flettner rotor is the smallest, and the efficiency result increased gradually with the number of the installed rotor. The other performance of WASP is also influenced by the sailing route, speed, and weather conditions. The installed wind turbine on the deck will affect only 1-4\% of fuels efficiency. The performance comparison between kites, soft sails, rigid sails, wind turbine and Flettner rotor can be seen in Table 1 .

\subsection{Challenges on Flettner rotor}

In this section, the challenges of the Flettner rotor are explained in three areas: parameter selection, weather condition, and economic aspect.

\subsubsection{Parameter selection}

In general, the installations number and the size of WASP technologies like the Flettner rotor affect the fuel efficiency result [9]. The design of the Flettner rotor corresponds to the calculation of aerodynamics. Several numbers have to be calculated and simulated to get an optimal lifting force such as height and diameter of the rotor, the diameter of the endplate, material of rotor, rotation of the rotor, and power consumption to spin the rotor [7], [11]-[13], [19], [24], [29]-[31].

Aspect ratio (AR) is the main factor that involves the effectiveness of the Flettner rotor. The lifting force produced by the Flettner rotor can reach higher than the maximum limit predicted if the aspect ratio has a very high number [13]. The number of aspect ratios modifies aerodynamic efficiency, which is the ratio between the height and diameter of the rotor. The lifting force will increase in line with the dimension of the rotor (the diameter $(d)$ and the high $(H))$ [30].
Another factor influencing the aerodynamics characteristics in the Flettner rotor's lifting forces is the spin ratio (SR) [30]. After touching the surface of the Flettner rotor, the free stream velocity can change into three possibilities: turbulent, laminar, and turbulent-laminar. But We cannot see the shedding and vortex formation when the $2.0 \leq \mathrm{SR}<3.0$ [13]. The required number to enumerate this ratio is the angular speed of the rotor $(\Omega)$, diameter $(d)$, and free stream velocity $(U)$ [13], [30]. Figure 2 shows the parameter of the Flettner rotor.

Another essential part of the Flettner rotor is the endplate or Thom plate, which is made on the rotor's top. This part has functions to optimize the aerodynamics efficiency on the surface of the rotor [30]. The endplate or Thom plate can increase the lifting force by almost double at a high-velocity ratio [13]. In the study of [13], to calculate the Flettner rotor's drag and lift force, a modified endplate $(1.0-3.0)$ is used with the same SR and AR. The calculation shows that a higher endplate will impact a higher lifting force produced by the Flettner rotor.

\subsubsection{Weather condition}

Speed optimization is an essential aspect for reducing fuel cost and emission of the ship, decreasing the emission by $23 \%$ yearly [8], [32]. Thus, forecasting wind and weather conditions is the central aspect influencing the ship's performance and fuel cost [14]. The methods of weather forecasting also evolving to invent an accurate output. The simplified set of equations or primitive equations to forecast the weather is called numerical weather prediction (NWP) [33].

The NWP equation was tested, simulated, and modified by many researchers and computers, resulting in a more accurate simulation model. The region and timeframe of weather forecasting influenced the accuracy of the calculation result: the smaller area and timeframe, the more precise the results [33]. But weather forecasting must also be integrated with the current and simulated vessel speed to improve the output accuracy.

Wind velocity is the most critical value that affects the Flettner rotor's produced lifting force [34]. The ship's sailing must integrate to the forecasted weather to optimize the efficiency result of the Flettner rotor. In ideal conditions, the Flettner rotor achieves maximum performance at actual wind directions of $120^{\circ}$ and $240^{\circ}$ from the vessel's direction [11],[13]. The fuel efficiency also will be higher in high actual wind velocity and slow ship speed [11]. Figure 3 shows the test results at a different angles of wind and velocity. 


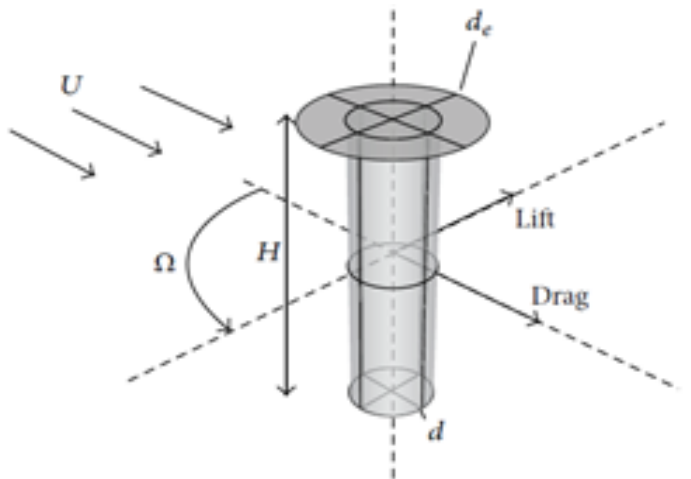

Figure 2. Flettner rotor and its parameter [13]

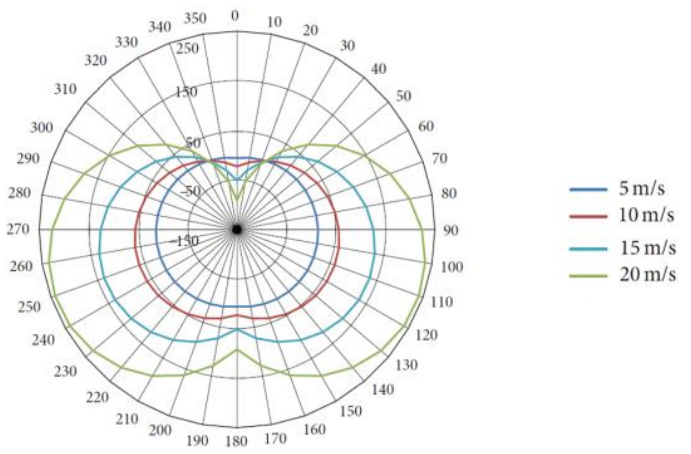

Figure 3. Trust output $(\mathrm{kN})$ from various wind velocity.

\subsubsection{Economic aspect}

Wind assisted-ship propulsive technologies (WASP) is a promising trend in the market for maritime transportation [9]. International regulation, companies, and environment activists campaign decarbonization to save the earth in the future [35]. This trend will change fossil fuel into renewable energy, which creates a new economic interest [14]. The usability of the Flettner rotor generally does not directly increase the profit of maritime logistics companies. Still, it can avoid the fund expenditure from the volatility of fuel prices and decrease the operational cost [9]. As shown in figure 4, the fuel prices volatility.

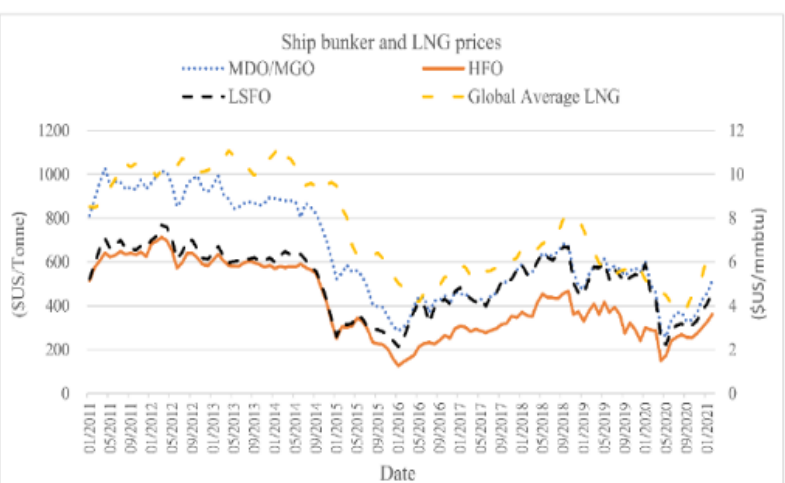

Figure 4. Fuel prices 2011-2021 [36]

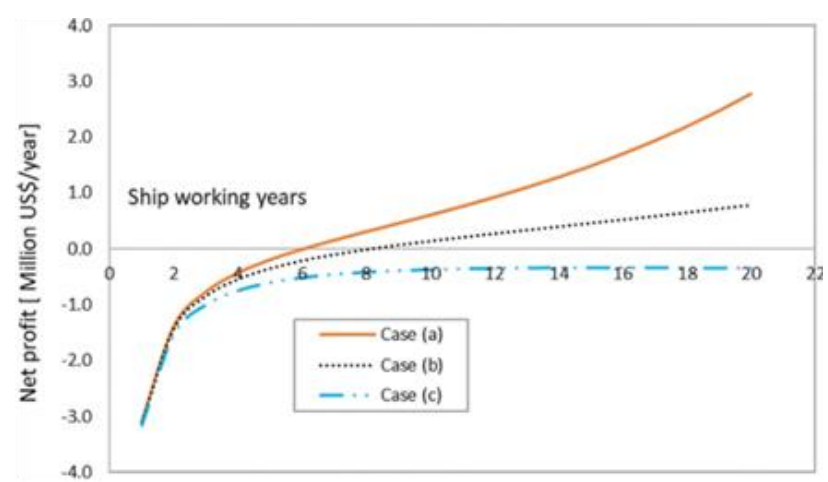

Figure 5. Ship's payback period and net saving value [11]

\section{CONCLUSION}

There are different types of wind assisted-ship propulsion (WASP) technology: rigid and soft sails, kites, wind turbines, and Flettner rotor. Compared with the Flettner rotor, kites and sails are more volatile. The lifting force of kites and sails are very dependent on the wind angle. The dimension of kites, on average, is also more significant than the Flettner rotor. However, the Flettner rotor can achieve fuel-saving up to $30 \%$ and increasing in line with the number of installed rotors. Compared to the wind turbine, the performance of the Flettner

Table 2. The operational comparison between each WASP technology

\begin{tabular}{|l|l|l|l|}
\hline & \multicolumn{1}{|c|}{ Fuel consumption } & \multicolumn{1}{|c|}{ Optimal wind direction } & \multicolumn{1}{c|}{ Dimension } \\
\hline Kites & $\begin{array}{l}\text { Potentially decrease } \\
\text { the fuel up to } 50 \%\end{array}$ & $\begin{array}{l}\text { Parallel with the direction of a } \\
\text { vessel }\end{array}$ & $\begin{array}{l}\text { Large of the kite with average } \\
\text { wide } 500 \mathrm{~m}^{2}\end{array}$ \\
\hline Soft sails & $\begin{array}{l}\text { Potentially decrease } \\
\text { the fuel up to 35\% }\end{array}$ & $\begin{array}{l}90 \text { and } 270 \text { degrees from the } \\
\text { direction of a vessel }\end{array}$ & $\begin{array}{l}\text { The total wide of the sail is } \\
1000 \mathrm{~m}^{2}\end{array}$ \\
\hline Rigid sails & $\begin{array}{l}\text { Potentially decrease } \\
\text { the fuel up to } 60 \%\end{array}$ & $\begin{array}{l}90^{\circ} \text { and } 270^{\circ} \text { from the direction } \\
\text { of a vessel }\end{array}$ & $\begin{array}{l}\text { More than three installed sails, } \\
\text { height and width more than } 25 \\
\text { m and } 9 \mathrm{~m} \text {, respectively }\end{array}$ \\
\hline Wind turbines & $\begin{array}{l}\text { Maximum fuel effi- } \\
\text { ciency only 4\% }\end{array}$ & Any direction & $\begin{array}{l}\text { The diameter of the turbine is } \\
38 \mathrm{~m} \text { and height } 20 \mathrm{~m}\end{array}$ \\
\hline Flettner rotor & $\begin{array}{l}\text { Potentially decrease } \\
\text { the fuel up to } 50 \%\end{array}$ & $\begin{array}{l}120^{\circ} \text { and } 240^{\circ} \text { from the direc- } \\
\text { tion of a vessel }\end{array}$ & $\begin{array}{l}\text { The minimum height is } 18 \mathrm{~m} \\
\text { with a diameter of only } 4-6 \mathrm{~m}\end{array}$ \\
\hline
\end{tabular}


rotor is much better. According to the study, the maximum fuel saving of wind turbines is only $1-4 \%$. The operational comparison between each WASP technology can be seen in Table 2.

On the other hand, the Flettner rotor application must be calculated using several parameters such as aspect ratio, spin ratio, and endplate to optimize the aerodynamic efficiency of the rotor. The performance of the Flettner rotor also can be worst if the weather is not in ideal condition. Economic aspects also play an essential role in the application of the Flettner rotor. The installation of the Flettner rotor leads to decreasing net profit in the first year, around 3 million USD, with a payback period of 6 -8 years. For further research, the selection of the Flettner rotor parameter should match with the ships type or deadweight tonnage of vessels. The Flettner rotor also should be tested and simulated in the actual weather condition in a specific region and timeframe.

\section{REFERENCES}

[1] Youmatter, "Climate Change: Meaning, Definition, Causes, Examples And Consequences," 2020.

[2] L. A. Ngongeh, I. K. Idika, and A. R. Ibrahim Shehu, "Climate change/global warming and its impacts on parasitology/entomology," Open Parasitol. J., vol. 5, no. 1, pp. 1-11, 2014, doi: 10.2174/1874421401405010001.

[3] K. International, "The pathway to green shipping," no. March, 2021.

[4] H. Ritchie and M. Roser, "CO2 and Greenhouse Gas Emissions," Our World in Data CO2 and Greenhouse Gas Emissions, 2017.

[5] J. Faber and Et al, "Fourth IMO Greenhouse Gas Study," 2021.

[6] R. Durth, "Sustainable maritime shipping and climate action," KfW Res., no. 279, 2020.

[7] E. Julià, F. Tillig, and J. W. Ringsberg, "Concept design and performance evaluation of a fossil-free operated cargo ship with unlimited range," Sustain., vol. 12, no. 16, 2020, doi: 10.3390/su12166609.

[8] H. Lee, N. Aydin, Y. Choi, S. Lekhavat, and Z. Irani, "A decision support system for vessel speed decision in maritime logistics using weather archive big data," Comput. Oper. Res., vol. 98, pp. 330342, 2018, doi: 10.1016/j.cor.2017.06.005.

[9] T. Chou, V. Kosmas, M. Acciaro, and K. Renken, "A comeback of wind power in shipping: An economic and operational review on thewind-assisted ship propulsion technology," Sustain., vol. 13, no. 4, pp. 1-16, 2021, doi: 10.3390/su13041880.

[10] B. Lyu, J. Kensrud, and L. Smith, "The reverse Magnus effect in golf balls," Sport. Eng., vol. 23, no. 1, pp. 1-7, 2020, doi: 10.1007/s12283-020-
0318-1.

[11] I. S. Seddiek and N. R. Ammar, "Harnessing wind energy on merchant ships: case study Flettner rotors onboard bulk carriers," Environ. Sci. Pollut. Res., 2021, doi: 10.1007/s11356-021-12791-3.

[12] I. S. Arief, A. Santoso, and A. Azzam, "Design of Flettner Rotor in Container Carrier 4000 DWT with CFD Method," Int. J. Mar. Eng. Innov. Res., vol. 2, no. 2, pp. 2-8, 2018, doi: 10.12962/j25481479.v2i2.2736.

[13] A. De Marco, S. Mancini, C. Pensa, G. Calise, and F. De Luca, "Flettner Rotor Concept for Marine Applications: A Systematic Study," Int. J. Rotating Mach., vol. 2016, 2016.

[14] M. S. Nazir et al., "Wind generation forecasting methods and proliferation of artificial neural network: A review of five years research trend," Sustain., vol. 12, no. 9, 2020, doi: 10.3390/su12093778.

[15] M. J. Grant and A. Booth, "A typology of reviews: An analysis of 14 review types and associated methodologies," Health Info. Libr. J., vol. 26, no. 2, pp. 91-108, 2009, doi: 10.1111/j.14711842.2009.00848.x.

[16] P. A. Derish and T. M. Annesley, "How to write a rave review," Clin. Chem., vol. 57, no. 3, pp. 388391, 2011, doi: 10.1373/clinchem.2010.160622.

[17] J. (university of wales) Rowley and F. (sheffield H. U. Slack, "Conducting a literature review," Manag. Res. news, vol. 27, no. 6, pp. 31-39, 2004, doi: https://doi.org/10.1108/01409170410784185.

[18] R. F. Baumeister and M. R. Leary, "Writing narrative literature reviews," Rev. Gen. Psychol., vol. 1, no. 3, pp. 311-320, 1997, doi: 10.1037/10892680.1.3.311.

[19] R. Lu and J. W. Ringsberg, "Ship energy performance study of three wind-assisted ship propulsion technologies including a parametric study of the Flettner rotor technology," Ships Offshore Struct., vol. 15, no. 3, pp. 249-258, 2020, doi: 10.1080/17445302.2019.1612544.

[20] S. R. Boonstra, "An investigation of the internal flow system behavior of a Turbosail," 2020.

[21] D. Nelissen, M. Traut, J. Kohler, W. Mao, J. Faber, and S. Ahdour, "Study on the analysis of market potentials and market barriers for wind propulsion technologies for ships," p. 127, 2016.

[22] P. Naaijen, V. Koster, and R. P. Dalliriga, "On the power savings by an auxiliary kite. Propulsion system," vol. 53, no. 1502, 2006.

[23] H. Ran, C.-E. Janson, and B. Allenström, “Auxilary Kite Propulsion Contribution to Ship Thrust," pp. $1-9,2014$. 
[24] M. Traut et al., "Propulsive power contribution of a kite and a Flettner rotor on selected shipping routes," Appl. Energy, vol. 113, pp. 362-372, 2014, doi: 10.1016/j.apenergy.2013.07.026.

[25] T. Smith, P. Newton, G. Winn, A. Grech, and L. Rosa, "Analysis techniques for evaluating the fuel savings associated with wind assistance," pp. 1-13, 2013.

[26] K. Ouchi, K. Uzawa, A. Kanai, and M. Katori, "'Wind Challenger' the Next Generation Hybrid Sailing Vessel," no. May, pp. 562-567, 2013.

[27] M. Bentin, D. Zastrau, M. Schlaak, D. Freye, R. Elsner, and S. Kotzur, "A new routing optimization tool-influence of wind and waves on fuel consumption of ships with and without wind assisted ship propulsion systems," Transp. Res. Procedia, vol. 14, pp. 153-162, 2016, doi: 10.1016/j.trpro.2016.05.051.

[28] A. B. Comer et al., "Rotors and bubbles: Routebased assessment of innovative technologies to reduce ship fuel consumption and emissions," 2019.

[29] DNV, "ECO FLETTNER Rotor Sail Stands the Test.".

[30] J. Siegl, I. S. Arief, and A. R. Hartawan, “Analysis of Energy Efficiency of Rotate Flettner Rotor Based on Variation 